\title{
Intracervical PGE2 gel application for cervical ripening and induction of labour: a clinical study
}

\author{
Shilpa Modi, Jayalaxmi Mahur*, Shashank V. S.
}

Department of Obstetrics and Gynecology, KBNIMS, Gulbarga, Karnataka, India

Received: 08 August 2019

Accepted: 19 August 2019

\section{*Correspondence:}

Dr. Jayalaxmi Mahur,

E-mail: jayachimkode@gmail.com

Copyright: (C) the author(s), publisher and licensee Medip Academy. This is an open-access article distributed under the terms of the Creative Commons Attribution Non-Commercial License, which permits unrestricted non-commercial use, distribution, and reproduction in any medium, provided the original work is properly cited.

\section{ABSTRACT}

Background: PGE2 gel (cerviprime) not only helps in cervical ripening but also sensitizes the uterine musculature to physiological PGE2 for generation and maintenance of uterine contractions. In the present study the efficacy of PGE2 intracerival gel for ripening and induction of labour has been reported.

Methods: This is a randomized prospective study of 80 cases admitted to the labour room during period of 2 years i.e. March 2017 to March 2019 in Department of Obstetrics and Gynecology, KBNIMS, Gulbarga, Karnataka. All patients had clear indications for termination of pregnancy. The initial bishop score determined prior to induction by pelvic examination. Under aseptic precautions PGE2 endocervical gel was instilled. The results analyzed for successful ripening, induction delivery interval, results in primigravida and multigravida with single instillation or reinstallation if required, mode of delivery and maternal and perinatal complications.

Results: The present study of 80 cases showed that a single application of intracervical PGE2 gel caused favorable changes in cervix by increasing Bishop score and shortened induction delivery interval with minimal side effects. Successful ripening with single application was achieved in $92.5 \%$ of cases (primi $42.5 \%$ and multi $50 \%$ ). Only $6.25 \%$ of primi's and $1.25 \%$ of multi's required reinstallation of PGE2 gel. Successful induction was achieved in $47.5 \%$ primi's and $50 \%$ multi's i.e. $97.5 \%$ cases.

Conclusions: The study concludes that single low dose intracervical PGE2 (cerviprime) gel proved to a safe, reliable and effective method for cervical ripening and induction of labour.

Keywords: Bishop score, Cervical ripening, Intracervical PGE2, Induction of Labour, Inductional delivery interval, Oxytocin augmentation

\section{INTRODUCTION}

The transcendent objective of obstetrics is that every pregnancy be wanted in that it culminates in a healthy baby.

Induction of labour with aim of achieving vaginal delivery has become an established and acceptable practice, when continuation of pregnancy become a threat to the life or wellbeing of the mother or her new born child.
Induction of labour is the initiation of uterine contraction before spontaneous onset of labour. Induction of cervical ripening is critical to the successful induction of labour in a pregnant patient whose cervix has not gone through the ripening process. ${ }^{1}$

Ripening of cervix refers to softening of cervix which is normally a physiologic process that precedes uterine contractions before and includes a highly complex biochemical process that ends with rearrangement and realignment of the collagen molecules. The cervix thins, 
softenens, relaxes and dilates in response to uterine contractions, allowing the cervix to easily pass over the presenting fetal part during the labour. ${ }^{1}$

Most commonly used methodology to evaluate the cervical ripening is Bishop score because it is simple and has the most predictive value. This score uses cervical dilatation, effacement, consistency, position and station of presenting part. A Bishop score of 6 or more is considered significant for cervical ripening and favorable for induction of labour.

A variety of methods have been developed to induce cervical ripening in the preparation of cervix for labour and delivery. Calder and Embrey (1974) reported that from 1973 various preparation of PGE2 in the form of gels, tablets and pessaries. Two forms of PGE2 (Dinoprostone) are available commercially. ${ }^{2-4}$ Cerviprime (In India), which is formulated as a gel $(3 \mathrm{gm}$ gel $/ 0.5 \mathrm{mg}$ Dinoprostone) is placed inside the cervix but not inside the internal os. Application can be repeated in 6 hours, not to exceed 3 doses in 24 hours. ${ }^{1,5,6}$

PGE2 Dinoprostone gel (cerviprime) not only helps in cervical ripening but also sensitizes the uterine musculature to physiological PGE2 for generation and maintenance of uterine contractions.

The gynaecological route of administration i.e. endocervical and intra vaginal offers an advantage of lower dose, easy application minimal discomfort to the patient, short medication delivery interval and few side effects.

Kore et al, mentioned that results of induction with PGE2 were equally favorable in primigravidae as well as multigravidae, fetal outcome was good in all cases. The induction delivery interval is more in patients with period of gestation less than 33 weeks as oxytocin receptor and uterine sensitivity is less at that time. ${ }^{7}$

Mukherjee et al, suggest that the induction delivery interval and caesarean section rate was also lowered in cases induced by intracervical PGE2 gel than oxytocin induction alone. $^{8}$

Brindley and Sokol mentioned that the use of low dose prostaglandin E2 preparation has been reported to increase the chances of successful initial, decrease the incidence of prolonged labor, and reduce total and maximal oxytocin doses. ${ }^{9}$

Embery et al, reported that the use of IV PGF2 to induce labour. $^{10}$

\section{METHODS}

This is a randomized prospective study done over a period of 2 years from March 2017 to March 2019, of total 80 cases admitted to the labour room in Department of Obstetrics and Gynecology, KBNIMS, Gulbarga, Karnataka, India.

The purpose of this study was to evaluate the safety and efficacy of intracervical PGE2 as a inducing agent in women with a unfavorable cervix, at term (Bishop Score $>6$ ).

All patient had clear indications for termination of pregnancy where further continuation of pregnancy was thought to be more hazardous than the proposed intervention.

\section{Inclusion criteria}

- Primigravida and multigravida

- Singleton pregnancy

- Cephalic presentation

- After 28 completed weeks of gestation

- Unfavourable cervix i.e. Bishop score $<6$ prior to induction

- With or without ruptured membranes.

\section{Exclusion criteria}

- Malpresentations

- Placenta praevia

- Preexisting non reassuring signs of fetal well being i.e. fetal distress

- Medical conditions like heart disease, bronchial asthma and glaucoma

- Hypersensitivity to prostaglandins

- Cephalopelvic disproportion.

After admission, detailed history was taken in all patients, general and obstetric examination done to find out uterine height, lie, presentation absence or presence of fetal heart sounds.

The initial bishop score determined prior to induction by pelvic examination under aseptic precautions.

Routine investigation like $\mathrm{Hb} \%$, urine routine examination and blood group and $\mathrm{Rh}$ typing were done, special investigations like RFT,LFT, platelet count, fundoscopy, in cases of PIH, BT, CT, coagulation profile in UID cases, USG done if required.

Gestational age was assessed after co-relating LMP, clinical examination and ultrasound report if available.

The procedure explained to the patient and informed consent taken in all cases.

The patient was placed in dorsal position and brought to the edge of the examination table. With strict aseptic precautions and with the help of sterile speculum and retractor with good light the cervix was visualized. 
Cervix and vagina gently sponged free of mucus and discharge.

The syringe is reassembled; the cannula of a prefilled syringe containing $2.5 \mathrm{ml}$ of PGE2 gel (cerviprime) was gently inserted upto the internal os and plunger gently pushed and the syringe gradually withdrawn to ensure deposition of the entire contents of PGE2 gel into the cervical canal below the internal os.

The patient remained recumbent for 30 minutes, patient was monitored for uterine contraction and fetal heart sound during this period.

After 6 hours patient was examined and changes in the cervical findings noted. Once the cervix was dilated $3 \mathrm{cms}$ or more amniotomy was done and color of liqour noted except in case of PIH (severe PIH, preeclampsia, eclampsia) early amniotomy was done.

If Bishop score increased to 6 or more but patient had ineffective uterine contractions augmentation with oxytocin drip was done(with $2.5 \mathrm{U}$ in $500 \mathrm{ml}$ IV fluid, starting with 8-10 drops per min and increased depending upon the response). In cases where there were no changes in the cervical score after 12 hours another application of PGE2 gel repeated with same follow up.

All patients had careful clinical monitoring of uterine contractions, fetal heart rate pattern and maternal vital parameters.
The progress of labour was assessed by noting the strength of uterine contractions. Descent of presenting part and dilatation of cervix.

Maternal side effects like hyperstimulation, nausea, vomiting and fever were noted. The Success of this induction in this study was aimed at achieving vaginal delivery within $24 \mathrm{hrs}$ of induction.

The results analyzed for successful ripening, induction delivery interval, results in primigravida and multigravida with single instillation or reinstallation if required, mode of delivery and maternal and perinatal complications.

A failed induction was defined as no change in cervical effacement or dilatation after six hours of adequate uterine contractions (3 contraction / 30-45 sec/10minutes) even after 3 inductions.

Patient with failed induction were managed with caesarean section.

\section{RESULTS}

In this study of 80 cases 19 cases $(23.75 \%)$ were in age group of $<20$ years which includes primi's $15(18.75 \%)$ and multi's $4(5 \%)$, about $42(65 \%)$ cases were in the age group of 21 to 30 years out of which 23 (28.75\%) were primi's and $29(36.25 \%)$ were multigravidas. Only 9 cases were more than 30 years of age which includes $1(1.25 \%)$ primigravida and $8(10 \%)$ multigravidas (Table1).

Table 1: Demographic characteristics age and parity.

\begin{tabular}{|llll|}
\hline Age & Primi $(\mathbf{n = 3 9})$ & Multi $(\mathbf{n = 4 1 )}$ & Total \\
\hline$<20$ years & $15(18.75 \%)$ & $4(5 \%)$ & $19(23.75 \%)$ \\
\hline $21-30$ years & $23(28.75 \%)$ & $29(36.25 \%)$ & $52(65 \%)$ \\
\hline$>30$ years & $1(1.25 \%)$ & $8(10 \%)$ & $9(11.25 \%$ \\
\hline
\end{tabular}

Table 2: Indication for induction.

\begin{tabular}{|llll|}
\hline Indication & Primi $(\mathbf{n}=39)$ & Multi $(\mathbf{n = 4 1})$ & Total \\
\hline Antepartum eclampsia & $17(21.25 \%)$ & $10(12.5 \%)$ & $27(33.75 \%)$ \\
\hline PIH & $11(13.75 \%)$ & $15(18.75 \%)$ & $26(32.5 \%)$ \\
\hline IUD & $6(7.5 \%)$ & $8(10 \%)$ & $14(17.5 \%)$ \\
\hline Congenital anomalies & $1(1.25 \%)$ & $5(6.25 \%)$ & $6(7.5 \%)$ \\
\hline PROM & $2(2.5 \%)$ & $3(3.75 \%)$ & $5(6.25 \%)$ \\
\hline Prolonged pregnancy & $2(2.5 \%)$ & - & $2(2.5 \%)$ \\
\hline
\end{tabular}

Among these 80 cases 39 were primigravidas and 41 were multigravidas among these 14 'were second gravida, 12 were third gravid, 7 were fourth gravid, 5 were fifth gravid, 2 sixth gravid and 1 gravida eight. Thus this study included grand multi's also, PGE2 gel application was done and labour was carefully monitored in these cases. Among the various indications for cervical ripening and induction of labour antepartum eclampsia and PIH (severe PIH, preeclampsia, imminent eclampsia) constituted the major group. In these 53 cases, 17 $(21.25 \%)$ primigravidas and $10(12.5 \%)$ multigravidas had antepartum eclampsia and $11(13.75 \%)$ primis and 15 (18.75\%) multis were diagnosed to have PIH. 14 (17.5\%) cases came with intrauterine death due to various causes 
out of which $6(7.5 \%)$ were primigravidas and $8(10 \%)$ were multigravidas $6(7.5 \%)$ cases had congenital anomalies of fetus as indication for induction 3 cases had anencephalic fetuses and 3 had other neutral tube defects.
Premature rupture of membranes (PROM) was indication in 5 cases of which $2(2.5 \%)$ were primis and $3(3.75 \%)$ were multigravidas, as reported in Table 2.

Table 3: Results in Primis with single instillation $(n=34)$.

\begin{tabular}{|llllll|}
\hline Indication & No. of cases & $\begin{array}{l}\text { Spontaneous } \\
\text { labour }\end{array}$ & $\begin{array}{l}\text { ARM + oxytocin } \\
\text { augmentation }\end{array}$ & $\begin{array}{l}\text { I-D interval (avg) } \\
\text { LSCS }\end{array}$ \\
\hline Antepartum eclampsia & 14 & 3 & 12 & 13.5 hours & 2 \\
\hline PIH & 9 & 1 & 8 & 16.7 hours & 1 \\
\hline IUD & 6 & 2 & 4 & 13 hours & - \\
\hline PROM & 2 & 1 & 1 & 10 hours & - \\
\hline Congenital anomalies & 1 & - & 1 & 16 hours & - \\
\hline Prolonged pregnancy & 2 & - & 2 & 13 hours & - \\
\hline Total & $\mathbf{3 4}(\mathbf{4 2 . 5 \% )}$ & $\mathbf{6 ( 1 7 . 5 4 \% )}$ & $\mathbf{2 8}(\mathbf{8 2 . 3 5 \% )}$ & Avg 13.7 hours & $\mathbf{3}(\mathbf{8 . 8 2 \%})$ \\
\hline
\end{tabular}

Table 4: Results in Multi's with single instillation $(n=40)$.

\begin{tabular}{|c|c|c|c|c|c|}
\hline Indication & No. of cases & $\begin{array}{l}\text { Spontaneous } \\
\text { labour }\end{array}$ & $\begin{array}{l}\text { ARM + oxytocin } \\
\text { augmentation }\end{array}$ & I-D interval (avg) & LSCS \\
\hline $\begin{array}{l}\text { Antepartum } \\
\text { eclampsia }\end{array}$ & 10 & 3 & 7 & 10.7 hours & 1 \\
\hline $\mathrm{PIH}$ & 15 & 5 & 10 & 9.26 hours & - \\
\hline IUD & 7 & 3 & 4 & 10.42 hours & - \\
\hline PROM & 5 & 2 & 3 & 9.4 hours & - \\
\hline Congenital anomalies & 3 & - & 3 & 14.66 hours & - \\
\hline Prolonged pregnancy & - & - & - & - & - \\
\hline Total & $40(40 \%)$ & $13(32.5 \%)$ & $27(33.75 \%)$ & 10.8 hours & $1(1.25 \%)$ \\
\hline
\end{tabular}

Among 39 primigravidas, 34 required only single application of these $6(17.54 \%)$ delivered spontaneously, $28(82.35 \%)$ cases required ARM plus oxytocin augmentation. The average I-D interval was 13.7 hours. 3 cases underwent LSCS for fetal distress as reported in Table 3.

Among 41 multigravidas, 40 required only single application of these 13 (32.5\%) delivered spontaneously, $27(33.75 \%)$ cases required ARM plus oxytocin augmentation. The average I-D interval was 10.8 hours. Only 1 case underwent LSCS for fetal distress.

Table 5: Bishop score changes after PGE2 gel instillation.

\begin{tabular}{|lll|}
\hline Bishop score (avg ) & Primi $(n=39)$ & Multi $(n=41)$ \\
\hline Initial & 2 & 2.1 \\
\hline After 6 hours & 5.3 & 6.4 \\
\hline After 12 hours & 7.6 & 8.2 \\
\hline
\end{tabular}

Cases of PROM had shorter I-D intervals as compared with other indications, as reveals in Table 4.

At the time of PGE2 gel instillation the average Bishop score was 2 in primis and 2.1 in multis. After $6 \mathrm{hrs}$ of instillation the score was 5.3 in primis and 6.4 in multis. After 12 hours of instillation it was 7.6 in primis and 8.2 in multis. This shows successfull ripening with single application showed improvement in Bishop score as reported in Table 5 .

With initial Bishop score 0-2, more number of multi's 13 $(16.25 \%)$ and $2(2.5 \%)$ primis delivered within 12 hours, $24(30 \%)$ primis and $9(11.25 \%)$ multis delivered within 13-24 hours, 9 cases i.e., 6(7.5\%) primis and $3(3.75 \%)$ multis had I-D interval of 24 hours and more as reported in Table 6.

With initial score $3-5,15$ cases $3(7.35 \%)$ primis and 12 (15\%) multigravidas delivered within 12 hours. 2 (2.5\%) primigravidas and $4(5 \%)$ multigravidas delivered within 13-24 hours and 2 (2.5\%) primis delivered after 24 hours or more, as mentioned in Table 6. Multigravidas had shorter ID Interval as compared to primigravidas. Cases with good initial score had shorter ID interval. Thus PGE2 is effective in shortening ID Interval as reported in Table 6.

About 6 cases required reinstallation out of which 5 were primis $(6.25 \%)$ and 1 was multigravida for all cases reinstallation was done only once. In all cases ARM and oxytocin augmentation was done. 3 cases delivered 
vaginally, one primi underwent LSCS for fetal distress, another primi with antepartum ecalmpsia with 31 weeks of gestation had failure of induction and was managed by LSCS.
The reinstallation delivery interval was 13 hours in primis and 8 hours in multis. Neonatal outcome was good in most of the cases as seen by Apgar score at 1 minute and 5 minutes, as seen in Table 7.

Table 6: Relation of Bishop score to I-D interval.

\begin{tabular}{|lllll|}
\hline Initial score & I-D interval & Primi $(\mathrm{n}=39)$ & Multi $(\mathrm{n}=41)$ & Total \\
\hline \multirow{3}{*}{$0-2$} & Within 12 hours & $2(2.5 \%)$ & $13(16.25 \%)$ & $15(18.75 \%)$ \\
\cline { 2 - 5 } & 13-24 hours & $24(30 \%)$ & $9(11.25 \%)$ & $33(41.25 \%)$ \\
\hline \multirow{3}{*}{$3-5$} & 24 and above & $6(7.5 \%)$ & $3(3.75 \%)$ & $9(11.25 \%)$ \\
& Within 12 hours & $3(7.35 \%)$ & $12(15 \%)$ & $15(18.75 \%)$ \\
\hline 13-24 hours & $2(2.5 \%)$ & $4(5 \%)$ & $6(7.5 \%)$ \\
\hline
\end{tabular}

Table 7: Results with reinstallation.

\begin{tabular}{|lllllll}
\hline Parity & Indication & Reinstallation & $\begin{array}{l}\text { ARM + oxytocin } \\
\text { augmentation }\end{array}$ & $\begin{array}{l}\text { Reinstallation } \\
\text { delivery interval }\end{array}$ & $\begin{array}{c}\text { Total I - D } \\
\text { interval }\end{array}$ & LSCS \\
\hline $\begin{array}{llllll}\text { Primi }(\mathrm{n}=5) \\
6.25 \%\end{array}$ & AE 3 & 1 & + & 13 hours & 25 hours & 1 \\
$\begin{array}{l}\text { Multi }(\mathrm{n}=1) \\
1.25 \%\end{array}$ & AE 2 & 1 & + & 8 hours & 20 hours & - \\
\hline
\end{tabular}

Average birth weight in primis was $2.2 . \mathrm{kgs}$ and $2.75 \mathrm{kgs}$ in multis. The low birth weight is due to prematurity and other factors like PIH etc.

The present study of 80 cases showed that a single application of intracervical PGE2 gel caused favorable changes in cervix by increasing Bishop score and shortened induction delivery interval with minimal side effects.

In present study, PIH (i.e. antepartum eclampsia, severe $\mathrm{PIH}$, preeclampsia and imminent eclampsia) constitutes the major group $(66.25 \%)$, as it is a common indications for cervical ripening and induction of labour.

Successful ripening with single application was achieved in $92.5 \%$ of cases (primi $42.5 \%$ and multi $50 \%$ ).

In the present study only 1 failure of induction occurred (primi with 31 weeks gestation with antepartum eclampsia) who was further managed by LSCS.

In present study primi with lower gestational age showed longer induction delivery interval.

In the present study spontaneous delivery with intervention occurred in $23.75 \%$ cases, ARM + Oxytocin augmentation was required in $70 \%$ cases. Only $6.25 \%$ cases underwent LSCS (indication being fetal distress in $5 \%$, and failed induction in $1.25 \%$ cases). In the most of the cases had lower gestational age and early amniotomy and oxytocin augmentation was indicated to hasten the labour.
Average birth weight in present study in primi $(2.2 \mathrm{kgs})$ and in multi $(2.75 \mathrm{~kg})$. Apgar score at $1 \mathrm{~min}$ and $5 \mathrm{mins}$ show good neonatal outcome. The used of PGE2 is associated with no adverse fetal side effects.

The aim of the present study is to evaluate PGE2 gel performance under a variety of conditions. Therefore patients with lower gestational age, ruptured membranes and previous caesarean section were included. Because of the small numbers these confounding factors may have influenced the result.

\section{DISCUSSION}

Data in the world literature seem to support the premise that the application of PGE2 gel into cervix promotes cervical ripening and facilitates induction of labour. ${ }^{11-13}$ There is limited information on dosing of PGE2 gel, level of monitoring required and the use of oxytocin after PGE2 gel administration. When compared with oxytocin prostaglandin reduces the risk of operative delivery and cesarean section. ${ }^{14,15}$

The success of induction of labour was found to be directly proportional to the Bishop score at instillation. In a study done by Calder et al, the cervical scoring has improved from a mean of 2.3 to 6.3 in 6 hours. The rate of improvement of bishop score, in this study was comparable to the results shown by Nilofour et al. ${ }^{15}$

In the present study the average induction delivery interval in primis is 13.7 hours and in multis is 10.8 hours which is comparable with other studies. In the study by 
Kore et al, average induction delivery interval in primi (11.4 hours) and in multis (7.6 hours) and study by Mukharjee et al, average induction delivery interval in primi(16.33 hours) and in multi (10.22 hours).,8 Multigravida had shorter induction delivery interval compared to primigravidas.

In the present study spontaneous delivery occurred in $23.75 \%$ cases, ARM+ oxytocin augmentation was required in $70 \%$ cases. Only $6.25 \%$ cases underwent LSCS whereas in the study by Behra et al spontaneous vaginal delivery occurred in $67 \%$ cases, ARM+ oxytocin augmentation was required in $15 \%$ cases and $18 \%$ cases underwent LSCS. The difference in incedence in the present study and other study could be due to differences in gestational age of the study group. ${ }^{16}$

Only $6.25 \%$ of primis and $1.25 \%$ of multi's required reinstationllation of PGE2 gel. In the study by Behra et al, reinstallation was required in $27 \%$ cases. Successful induction was achieved in $47.5 \%$ primis and $50 \%$ multi's i.e. $97.5 \%$ cases. In study by Behra et al, successful induction was achieved in $82 \%$ cases. Thus single low dose application of PGE2 gel proved effective for cervical ripening in the present study. ${ }^{16}$

In present study, PIH (i.e. antepartum eclampsia, severe $\mathrm{PIH}$, preeclampsia and imminent eclampsia) constitutes the major group $(66.25 \%)$, whereas in Nilofour et al study shows prolonged pregnancy $(40 \%)$ and PROM (18.88\%) as the common indications for cervical ripening and induction of labour. ${ }^{15}$

The incidence of maternal complications like nausea, vomiting and hyperstimulation or precipitate labour was not seen in any case. The major maternal complication seen was PPH. 3 cases had traumatic PPH due to cervical/perineal tear associated with outlet forceps application. Only one multigravida had atonic PPH. This cannot be directly related to PGE2 gel. Other studies like Behra et al nausea and vomiting was seen in $1 \%$ cases and hyperstimulation in $2 \%$ cases. $^{16}$

Fetal distress occurred in $5 \%$ of cases in present study and Behra et al had $3 \%$ incidence of fetal distress. ${ }^{16}$ In our study the incidence of birth asphyxia was $10 \%$ compared to $3 \%$ inthe study by Behra et al. This could be due to prematurity and PIH. These neonatal complications cannot be attributed to the use of PGE2 gel as other confounding factors are present. ${ }^{16}$

\section{CONCLUSION}

In recent years modern obstetric techniques have greatly increased the safety and reliability of labour. The use of intracervical PGE2 causes cervical ripening and enhances Bishop score. It may also enhance labour in many cases. It is safe and acceptable method for induction of labour in patients with unfavourable cervix. The role of PGE2 gel and oxytocin in unfavourable cervix is complementary.
Intracervical PGE2 gel application with or without oxytocin augmentation plays a significant role in reducing the induction delivery interval and cesarean section rate. The incidences of maternal and fetal complication are low. Hence the drug can be recommended for routine use with poor Bishop score.

To conclude single low dose intracervical PGE2 (cerviprime) gel proved to a safe, reliable and effective method for cervical ripening and induction of labour.

\section{ACKNOWLEDGMENTS}

Authors would like to thank all the participants of this study for their full cooperation and support.

\section{Funding: No funding sources}

Conflict of interest: None declared

Ethical approval: The study was approved by the Institutional Ethics Committee

\section{REFERENCES}

1. Krishnandu G. Induction of Labour. Principles Protocols Practices FOGSI - ICOG; 2018:40-47.

2. Arias F. Pharmacology of Oxytocin and prostaglandins. Clin Obstet Gynecol. 2000;43:45568.

3. Witter FR. Prostaglandin E2 preparations for preinduction cervical ripening. Clin Obstet Gynecol. 2000;43:469-74.

4. Goetzl L. Methods of cervical ripening and labour induction: Pharmacologic. Clin Obstet Gynecol. 2014;57:377-90.

5. Calder AA, Embrey MP. Prostaglandins and the unfavorable cervix. Lancet. 1973;2(7841):1322-3.

6. Cunningham FG, Lenovo KJ, Bloom SL, Dashe JS, Hoffman BL, Casey BM, et al. Induction and augmentation of labour. Williams Obstetrics, New York (NY): McGraw-Hill; 2014;25:506-7.

7. Kore S, Karnik H, Arora P, Khedekar GN, Vidya PR. Use of endocervical PGE2 (Dinoprostone) gel for induction of labour. J Obset Gynaec India. 1996;4:482-6.

8. Mukharjee K, Neogi V, Gangooli U, Mishra R. A comparative study of induction of labour by PGE2 and oxytocin and its outcome. J Obstet Gynaec India. 1996;46(5):631.

9. Brindley BA, Sokol RJ. Induction and augmentation of labour: basis and methods for current practice. Obset Gynecol Survey. 1988;43:730-43.

10. Embrey MP, Calder AA, Hillier K. Extraamniotic prostaglandin E2 for induction of labour at term. J Obset Gynaecol Br Commonwealth. 1974;81:39-44.

11. Thiery M, Dewster JM, Parewijick W, Noah ML. Endocervical prostaglandin E2 gel for preinduction cervical softening. Clin Obstet Gynecol. 1984;27:429-39.

12. Noah ML, Decoster JM, Fraser W. Preinduction cervical softening with endocervical PGE2 gel. A 
multicenter trial. Acta Obstet Gynecol Scand. 1987;66:3-7.

13. Trofalter KF. Endocervical prostaglandin E2 gel for preinduction cervical ripening. Clinical trial results. J Reprod Med. 1993;38(1 suppl):78-82.

14. Pollnow DM, Broekhuizen FF. Randomized double blind trial of PGE2 intravaginal gel versus low dose oxytocin for cervical ripening before induction of labour. Am J Obstet Gynecol. 1996;174:1910-3.

15. Niloufur Syed B. A study of intracervical PGE2 gel for cervical ripening and induction of labour. Int $\mathrm{J}$ Contemp Med Res. 2018;5(3):C4-C7.
16. Behra RC, Kandoth SK, Goyal BK. Labour induction in unfavourable cervix (a prospective study). J Obstet Gynecol India. 1997;47(1):53-61.

Cite this article as: Modi S, Mahur J, Shashank VS. Intracervical PGE2 gel application for cervical ripening and induction of labour: a clinical study. Int J Reprod Contracept Obstet Gynecol 2019;8:352834. 